\title{
A plasmid-cured Chlamydia muridarum strain displays altered plaque morphology and reduced infectivity in cell culture
}

\author{
Catherine M. O'Connell and Kristy M. Nicks \\ Department of Microbiology and Immunology, UAMS, 4301 West Markham, Little Rock, AR \\ 72205, USA
}

Correspondence

Catherine M. O'Connell

oconnellcatherine@uams.edu

Received 3 November 2005

Revised 28 February 2006

Accepted 8 March 2006

\begin{abstract}
A highly conserved cryptic plasmid is present in Chlamydia trachomatis yet naturally occurring plasmid-deficient isolates are very rare. This paper describes the isolation and characterization of a plasmid-deficient strain of C. muridarum, using novobiocin as a curing agent. Plasmid-deficient derivatives of C. muridarum strain Nigg were generated at high efficiencies (4-30\%). Phenotypic characterization revealed that the cured derivative was unable to accumulate glycogen within intracytoplasmic inclusions. In addition, this strain formed small plaques at a reduced efficiency compared to the wild-type parent.
\end{abstract}

\section{INTRODUCTION}

Chlamydiae are obligate intracellular bacterial parasites of eukaryotic cells that cause a broad spectrum of clinically distinct diseases in animals and humans. A highly conserved plasmid of approximately $7 \cdot 5 \mathrm{~kb}$ is present in almost all strains of Chlamydia trachomatis, with copy numbers estimated to range from 4 (Pickett et al., 2005) to 10 (Tam et al., 1992) copies per cell. The role of this plasmid is unknown. However, all eight predicted ORFs are expressed at the RNA level (Fahr et al., 1992; Pearce et al., 1991; Belland et al., 2003) and at least one of the plasmid-encoded proteins is expressed during infection (Comanducci et al., 1993). Naturally occurring plasmid-deficient clinical isolates are extremely rare; only three strains have been described (Peterson et al., 1990; Farencena et al., 1997; Stothard et al., 1998). In contrast, Matsumoto et al. (1998) described the isolation and characterization of three plasmid-deficient C. trachomatis strains that occur naturally in tissue-culturepropagated cultures at an estimated rate of $1 \%$. The derivatives identified by these authors appeared unable to accumulate glycogen within the intracytoplasmic inclusions that are formed by the bacteria as they grow. No other phenotypic changes were detected that could be attributed to the presence of the plasmid (Miyashita et al., 2000).

Currently, a genetic system for use in chlamydiae is lacking. A better understanding of the mechanisms by which the cryptic plasmid, a potential gene delivery vector, is maintained, and the ability to generate at high efficiency plasmid-deficient derivatives of the most highly characterized chlamydiae for use as recipient strains would advance progress in this area. We describe the curing of the mouse-virulent Chlamydia muridarum using novobiocin.

Abbreviation: i.f.u., inclusion-forming units.
Characterization of the cured strain revealed, in addition to a defect in the ability to accumulate glycogen, an in vitro attachment or uptake defect that could be partially overcome by centrifugation.

\section{METHODS}

Strains, cell lines and culture conditions. The chlamydial strains used in the course of this study are shown in Table 1. Cell culture media and reagents were purchased from Mediatech. The chlamydiae were routinely cultured in multiwell dishes (24- or 6well) containing confluent monolayers of McCoy cells that were infected at an approximate m.o.i. of $0.5-1$, unless otherwise stated, before being centrifuged at $1600 \mathrm{~g}$ for $1 \mathrm{~h}$ at $37^{\circ} \mathrm{C}$. The infective inoculum was then removed and replaced with $1 \times$ Dulbecco's modified Eagle's medium (DMEM) supplemented with $10 \%$ heatinactivated fetal bovine serum (FBS), $20 \mu \mathrm{g}$ gentamicin $\mathrm{ml}^{-1}$ and $0 \cdot 1 \mu \mathrm{g}$ cycloheximide $\mathrm{ml}^{-1}$. Where indicated, novobiocin (Sigma) was added at the concentrations indicated (up to $250 \mu \mathrm{g} \mathrm{ml}^{-1}$ ) at $4 \mathrm{~h}$ post-infection. Concentrations of novobiocin below $1000 \mu \mathrm{g}$ $\mathrm{ml}^{-1}$ are not cytotoxic for cells in culture (Hussy et al., 1986) and this was qualitatively confirmed by evaluating the ability of uninfected cells to exclude Trypan blue dye $48 \mathrm{~h}$ after treatment with the drug. Infected cells were then incubated at $37^{\circ} \mathrm{C}, 5 \% \mathrm{CO}_{2}$ for $36 \mathrm{~h}$ before being harvested into SPG buffer $(218 \mathrm{mM}$ sucrose, $3.8 \mathrm{mM}$ $\mathrm{KH}_{2} \mathrm{PO}_{4}, 7 \cdot 2 \mathrm{mM} \mathrm{K} \mathrm{HPO}_{4}, 4.9 \mathrm{mM}$ L-glutamate, $\mathrm{pH} \mathrm{7.2)}$, sonicated and stored at $-80^{\circ} \mathrm{C}$. Bacteria were subsequently titrated by plaque assay or as inclusion-forming units (i.f.u.). Briefly, i.f.u. estimates were performed by infecting confluent McCoy cell monolayers growing in 96-well dishes with 10 -fold dilutions of the chlamydial inoculum, centrifuging at $1600 \mathrm{~g}$ for $1 \mathrm{~h}$ at $37^{\circ} \mathrm{C}$ before replacing the cell culture medium as described above. After approximately $30 \mathrm{~h}$ incubation at $37^{\circ} \mathrm{C}, 5 \% \mathrm{CO}_{2}$, the cells were fixed with absolute methanol, then stained using a genus-specific fluorescently tagged monoclonal antibody (Bio-Rad) before inclusions were counted (Kelly et al., 1996).

Plaque-forming assay. Dilutions of the freshly harvested, novobiocin-treated bacteria were inoculated by centrifugation at $1600 \mathrm{~g}$ 
Table 1. Bacterial strains

\begin{tabular}{|lll|}
\hline Strain & \multicolumn{1}{c|}{ Description } & Source or reference \\
\hline C. muridarum Nigg & Wild-type, mouse virulent & Nigg (1942) \\
C. muridarum CM972 & Plasmid-deficient derivative of strain Nigg & This study \\
C. trachomatis 25667R & Plasmid-deficient clinical isolate, serovar L2 & Peterson et al. (1990) \\
C. trachomatis CT599 & Plasmid-deficient clinical isolate, serovar E & Stothard et al. (1998) \\
\hline
\end{tabular}

for $1 \mathrm{~h}$ at $37^{\circ} \mathrm{C}$ onto confluent monolayers of McCoy cells grown in 6-well tissue culture dishes. The infective inoculum was then removed and the monolayers were overlaid with $1 \times$ DMEM, $10 \%$ FBS, $0 \cdot 25 \%$ agarose, $0 \cdot 01 \mu \mathrm{g}$ cycloheximide $\mathrm{ml}^{-1}$, and incubated at $37^{\circ} \mathrm{C}, 5 \% \mathrm{CO}_{2}$ for $5-7$ days, to allow plaques to form. To visualize plaques, the solid overlay was removed and the monolayer stained with $0.025 \%$ neutral red in $1 \times$ PBS $(130 \mathrm{mM} \mathrm{NaCl}, 0 \quad 8 \mathrm{mM}$ $\left.\mathrm{Na}_{2} \mathrm{HPO}_{4}, 0 \cdot 2 \mathrm{mM} \mathrm{KH} \mathrm{KO}_{4}, \mathrm{pH} 7 \cdot 4\right)$. Plaque purifications were carried out by picking individual plaques into $200 \mu \mathrm{l}$ SPG buffer. The resulting plaque suspensions were then sonicated to lyse the cells and appropriate dilutions replated as described above. Expansion of plaques arising after novobiocin treatment or during sequential plaque purification was achieved by the picking of individual plaques as described, then using this material to infect, via centrifugation, individual wells of a 24-well dish containing confluent monolayers of McCoy cells for a single passage $(\sim 40 \mathrm{~h})$ before harvesting in SPG buffer. An additional passage was then performed in an identical manner using $\sim 1 / 10$ th of the well harvest as inoculum. Two sequential rounds of infection usually resulted in stocks of $\sim 1-2 \times 10^{8}$ i.f.u. $\mathrm{ml}^{-1}$ that were then used for further analysis. Plaquing efficiency under different culture conditions was evaluated by the titration of individual strains by a plaque-forming assay, with indicated modifications, in parallel with titration to estimate i.f.u. (Kelly et al., 1996). The efficiency of plating (e.o.p.) is calculated as p.f.u. $\mathrm{ml}^{-1} /$ i.f.u. $\mathrm{ml}^{-1}$.

lodine staining of chlamydia-infected cells. McCoy cells cultured on glass cover slips in multiwell plates were infected as described above. After $40 \mathrm{~h}$ incubation, the culture medium was removed and the monolayer rinsed several times with $1 \times$ Hanks' balanced salt solution (HBSS) before being fixed and stained with iodine (Schachter \& Dawson, 1978) in order to detect the presence of accumulated glycogen. Stained cells were immediately photographed using a digital camera system and SPOT version 4.0.6 software from Diagnostic Instruments.

Detection of chlamydial plasmid or chromosome by PCR and Southern blotting. Genomic material was routinely prepared for use as PCR template by boiling chlamydial suspensions containing $10^{7}$ i.f.u. $\mathrm{ml}^{-1}$ for more for $10 \mathrm{~min}$, before diluting 10 -fold in distilled $\mathrm{H}_{2} \mathrm{O}$. PCR amplifications were performed using $5 \mu$ of this preparation in a $20 \mu \mathrm{l}$ reaction volume. Template preparations were amplified as follows: $95{ }^{\circ} \mathrm{C}, 30 \mathrm{~s} ; 50{ }^{\circ} \mathrm{C}, 30 \mathrm{~s} ; 72{ }^{\circ} \mathrm{C}, 30 \mathrm{~s}$ for 40 amplification cycles using the primer pairs described in Table 2.
Genomic DNA for Southern hybridization analysis was purified from chlamydia-infected cells using a kit obtained from Epicentre Biotechnologies. A plasmid-specific DIG-labelled (Roche Diagnostics) probe was generated by labelling, via random hexamer priming, the $7 \cdot 5 \mathrm{~kb}$ PstI fragment of pCT01 (O'Connell \& Maurelli, 1998) which comprises the entire cryptic plasmid of C. trachomatis strain $\mathrm{L} 2 / 434 / \mathrm{Bu}$.

\section{RESULTS}

\section{Effect of novobiocin treatment on replication of chlamydiae}

Treatment with sublethal doses of novobiocin can influence the extent of DNA supercoiling (Luttinger, 1995), affecting gene expression and rendering the antibiotic an effective plasmid-curing agent (Gado et al., 1987; Hooper et al., 1984; Wolfson et al., 1983). Thus we were interested in investigating the possibility that novobiocin treatment might enhance the rate of plasmid loss from C. trachomatis. We titrated the impact of increasing amounts of novobiocin on chlamydial growth using C. muridarum Nigg (MoPn) (Nigg, 1942), a strain that previously had not been demonstrated to be curable. Increasing amounts of freshly diluted novobiocin were added to the cell culture medium $4 \mathrm{~h}$ postinfection to ensure that normal uptake and differentiation to the reticulate body (RB) form were not inhibited by antibiotic treatment. The yields of novobiocin-treated bacteria were measured by plaque assay (Fig. 1) at harvest $(\sim 40 \mathrm{~h}$ after infection). Although the impact of drug treatment on the recovery of infectious chlamydiae was minimal at the lowest concentrations assayed, a novobiocin concentration of $62.5 \mu \mathrm{g} \mathrm{ml}^{-1}$ reduced the relative infectious yield of bacteria by at least 100 -fold. By extrapolation from studies with other micro-organisms (Gado et al., 1987; Hooper et al., 1984; Wolfson et al., 1983), we anticipated that plasmid curing would be most effective at concentrations where $\sim 99 \%$ of bacterial growth was inhibited by the antibiotic.

Table 2. PCR primers

\begin{tabular}{|lcc|}
\hline Name & \multicolumn{1}{c|}{ Sequence } & Product size (bp) \\
\hline tufA F4 (sense primer) & 5'-CACTACGCTCACGTGGACTG-3' $^{\prime}$ & 593 \\
tufA R4 & 5'-CTCTCCTGCACGACCTTCTG-3' $^{\prime}$ & \\
pMoPn F2 (sense primer) & $5^{\prime}$-TGTCACAGCGGTTGCTCTAA-3' & 317 \\
pMoPn R2 & 5'-CTATGCTGCAAGGAGGTAAG-3' & \\
\hline
\end{tabular}




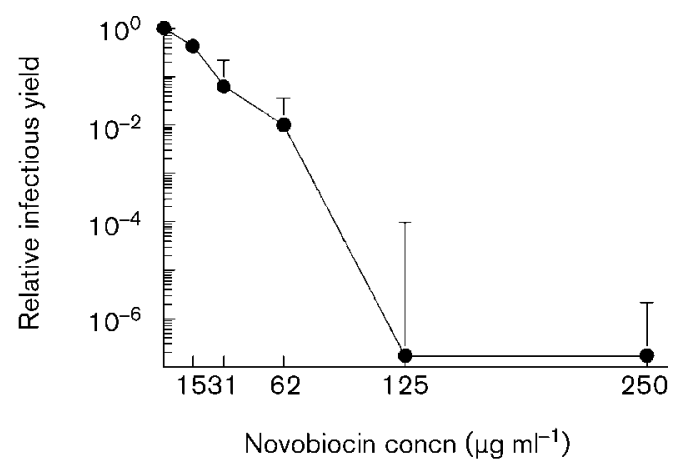

Fig. 1. Effect of novobiocin treatment on replication of C. muridarum strain Nigg. The novobiocin-treated chlamydiae were harvested and plated by centrifugation to generate individual plaques for titration. The relative infectious yield of strain Nigg at each novobiocin concentration was derived by normalizing the total infectious yield per treated population against the yield from the untreated control. The graph is drawn from the mean of two experiments with each point assayed in duplicate \pm SD.

To examine whether novobiocin treatment had cured the plasmid, individual plaques were picked at random from the $62.5 \mu \mathrm{g} \mathrm{ml}^{-1}$ plate, where we had observed $<90 \%$ inhibition and thus might expect optimal plasmid curing. The plaques were then sequentially plaque purified three to five times, before being amplified to high titre. Each of the plaque-purified isolates was then screened by PCR for the presence of the cryptic plasmid. A chromosome-specific target, the tufA gene encoding the elongation factor Ef-Tu involved in protein biosynthesis, was used as control. In two independent experiments, the frequency of novobiocintreated isolates for which a plasmid-specific PCR product was not detected ranged from 4 to $30 \%$ ( 1 of 24 and 8 of 24 ) (Fig. 2a). An identical screen was performed on 73 plaque isolates that were picked from untreated control plates. No plasmid-deficient isolates were identified within this group ( 0 of 55 and 0 of 18). A single representative of the plasmiddeficient isolates was selected for continued analysis and designated C. muridarum strain CM972. The absence of plasmid in CM972 was confirmed by Southern hybridization analysis using the entire cryptic plasmid from $C$. trachomatis $\mathrm{L} 2 / 434 / \mathrm{Bu}$ as probe (Fig. $2 \mathrm{~b}$ ).

To confirm the parental background of strain CM972, we performed immunofluorescent staining of infected McCoy cells using the strain-specific mouse monoclonal antibody M40, obtained from Dr Ellena Peterson (University of California, Irvine). This antibody is directed against a VD1 epitope of the major outer-membrane protein (MOMP) expressed by C. muridarum Nigg. The bacteria within inclusions formed by both the Nigg and the plasmid-deficient CM972 strains stained positively (Fig. 2c, d). The genome of C. muridarum Nigg has been sequenced (Read et al., 2000) so we further confirmed the identity of the CM972 by amplifying and sequencing a region of $o m p A$, the gene that (a)

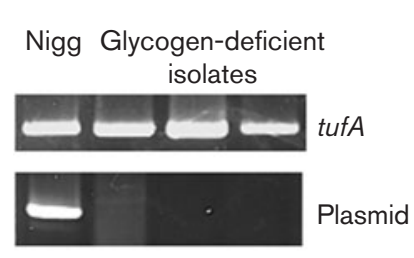

(c)

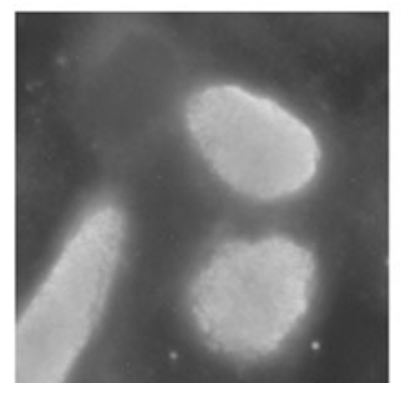

(b)

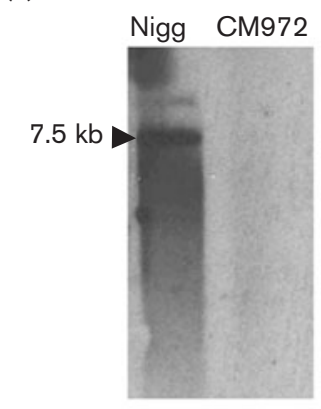

(d)

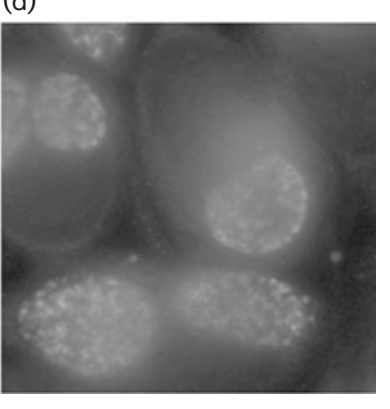

Fig. 2. Characterization of plasmid-deficient derivatives of $C$. muridarum. $(a, b)$ The results of PCR screening (a) or Southern hybridization (b) for detection of the cryptic plasmid. (a) Equal amounts of template were added to PCR reactions containing primers directed against either the cryptic plasmid (pMoPN F2/R2), or the chlamydial genome (tufF4/R4). (b) Total genomic DNA $(3 \mu \mathrm{g})$ was isolated from C. muridarum strains Nigg and CM972 and digested with Pstl before being separated on a $1 \%$ agarose gel and transferred to a nylon membrane before using DIG-labelled cryptic plasmid of C. trachomatis L2/434/ $\mathrm{Bu}$ as probe. (c, d) McCoy cells infected with either strain Nigg (c) or strain CM972 (d), were fixed and stained with the strain-specific mouse monoclonal M40 $24 \mathrm{~h}$ post-infection. The monoclonal antibody was then detected using a goat antimouse FITC-conjugated antibody with Evans blue (1:1000) staining of cytoplasm before being photographed at $1000 \times$ magnification.

encodes MOMP, using the primer set BII and FII (Dean et al., 1995). The DNA sequence of the amplified fragment was identical to both the parental Nigg strain and the published sequence (data not shown).

\section{Plasmid-deficient $\boldsymbol{C}$. muridarum is defective in accumulation of glycogen within inclusions}

Previously, the three plasmid-deficient strains isolated by Matsumoto et al. (1998) were shown to be unable to accumulate glycogen, as detected by iodine stain, within the intracytoplasmic inclusion formed by the growing bacteria. We used iodine staining of $40 \mathrm{~h}$ infected McCoy cells to determine the relative glycogen content of inclusions containing the Nigg or the CM972 strain of C. muridarum and found that the plasmid-minus CM972 strain was severely deficient in the accumulation of glycogen compared 

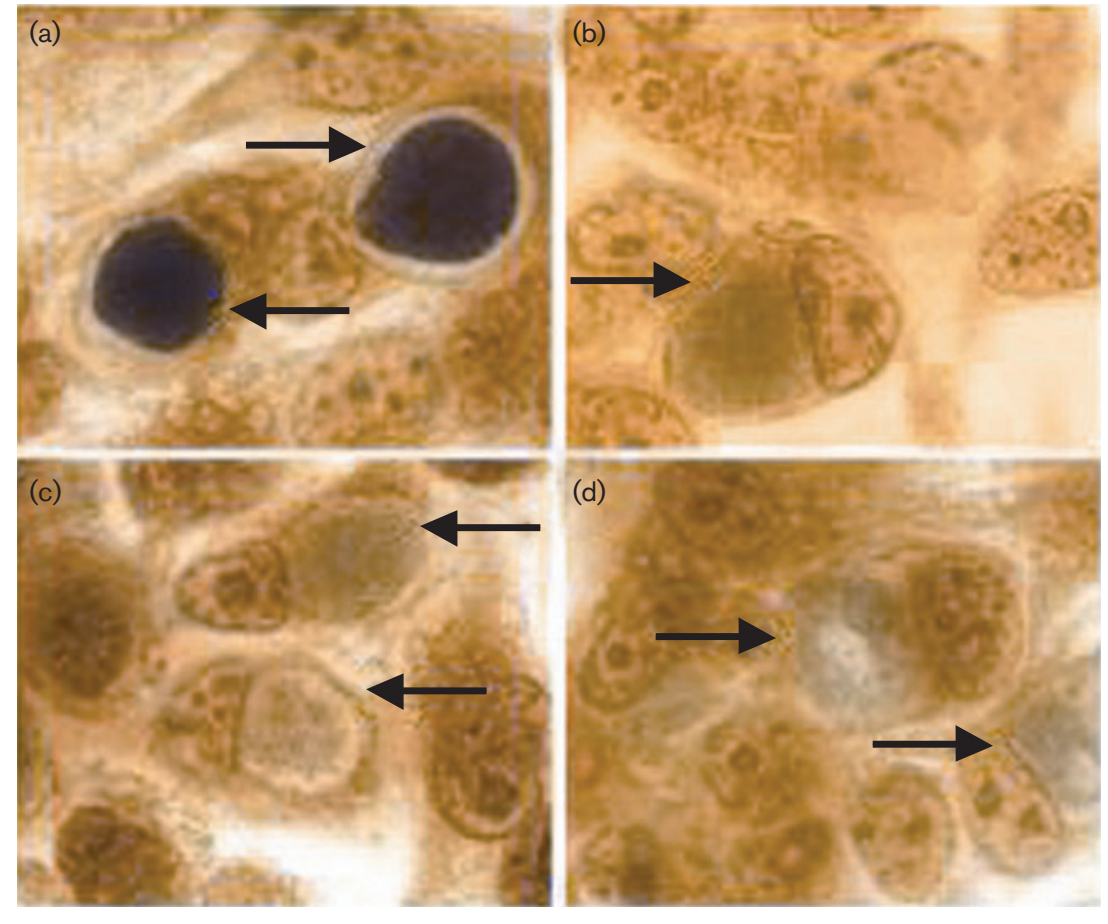

Fig. 3. Glycogen accumulation within inclusions is not observed in the plasmid-deficient C. muridarum $\mathrm{CM} 972$, or in the plasmiddeficient clinical isolates $C$. trachomatis 25667R and CT599. (a-d) In a representative parallel experiment, chlamydia-infected McCoy cells were fixed and stained with iodine $40 \mathrm{~h}$ post-infection before being photographed at $1000 \times$ magnification. (a) C. muridarum Nigg; (b) C. muridarum CM972; (c) C. trachomatis 25667R; (d) C. trachomatis CT599. Arrows indicate the location of chlamydial inclusions. to the plasmid-containing Nigg strain (Fig. 3a, b). Interestingly, the clinical isolates $C$. trachomatis $25667 \mathrm{R}$ and CT599, known to lack the cryptic plasmid, were also found to be deficient in their ability to accumulate glycogen (Fig. 3c, d). Novobiocin treatment of Nigg-infected McCoy monolayers resulted in variable iodine staining of inclusions, ranging from non-staining inclusions to inclusions that appeared to contain only patchy depositions of iodine to inclusions that resembled those formed by untreated bacteria (data not shown). Analysis of the 48 plaquepurified isolates derived from the initial drug-treated bacteria screens revealed that only the plasmid-cured isolates stained negatively with iodine, indicating that glycogen accumulation may be regulated from the plasmid.

\section{Plasmid-deficient $C$. muridarum form smaller plaques at reduced efficiency}

While attempting to determine the effectiveness of novobiocin as a plasmid-curing agent, we observed that when the drug-treated C. muridarum were plated in a plaque assay using manual agitation, e.g. rocking (Banks et al., 1970), to inoculate the monolayers, only iodine-positive, plasmidcontaining isolates were recovered. In contrast, if the bacteria were inoculated into the plaque assay via centrifugation, both plasmid-containing wild-type and plasmiddeficient, iodine-negative isolates could be recovered. Furthermore, attempts to plaque the clinical isolates $C$. trachomatis 25667R and CT599 without centrifugation were unsuccessful. We reasoned that loss of the cryptic plasmid might be associated with a reduced ability to form a plaque. To test the efficiency with which $C$. muridarum Nigg and strain CM972 were able to form plaques, the strains were titrated in parallel experiments by plaque assay with or without centrifugation. The results of this experiment are shown in Table 3. It is clear from these data that, while the e.o.p. for both strains approached 1 when the inoculum was applied to the monolayers during centrifugation, the ability of strain Nigg to form plaques was reduced $\sim 35$-fold when the inoculum was applied in the absence of centrifugation. An even more striking difference was observed for strain CM972, whose ability to plaque was reduced an additional $\sim 150$-fold when the strain was applied to the monolayers without centrifugation. In addition, plaques formed by strain CM972 were approximately one-half the diameter of those of the parental strain in parallel experiments, even when the bacteria had been centrifuged onto the monolayers (Fig. 4). To exclude the possibility that the differences in plaque size were due to a

Table 3. Plaquing efficiency of C. muridarum strains Nigg and CM972 on McCoy cells

Values shown are the mean of two independent experiments performed in duplicate and are expressed as the mean e.o.p. \pm SE. The e.o.p. was calculated by dividing p.f.u. $\mathrm{ml}^{-1}$ under each condition by i.f.u. $\mathrm{ml}^{-1}$ (determined by centrifugation onto monolayers, as described in Methods).

\begin{tabular}{|c|c|c|}
\hline \multirow[t]{2}{*}{ Strain } & \multicolumn{2}{|c|}{ Efficiency of plating } \\
\hline & Centrifugation & No centrifugation \\
\hline Nigg & $4.95 \times 10^{-1} \pm 3 \cdot 28 \times 10^{-1}$ & $1 \cdot 38 \times 10^{-2} \pm 5 \cdot 79 \times 10^{-3}$ \\
\hline CM972 & $6.02 \times 10^{-1} \pm 2 \cdot 35 \times 10^{-2}$ & $1 \cdot 13 \times 10^{-4} \pm 7 \cdot 15 \times 10^{-5}$ \\
\hline
\end{tabular}


C. muridarum Nigg

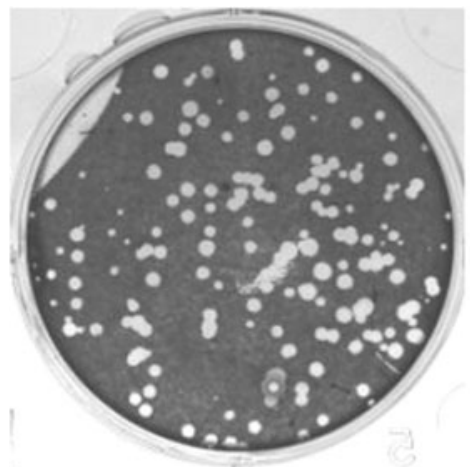

C. muridarum 972

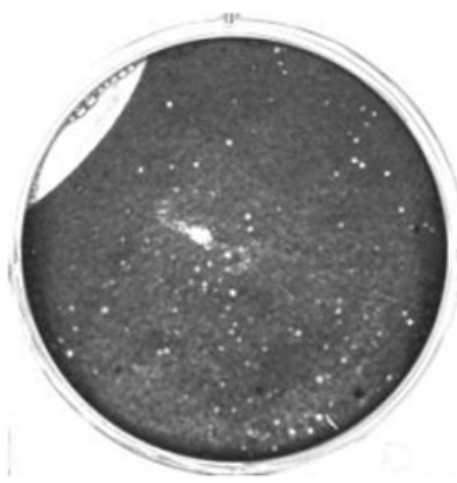

Fig. 4. Plaques formed by plasmid-deficient C. muridarum are reduced in size. Single plaques formed by $C$. muridarum strains Nigg $(2 \cdot 82 \pm 1 \cdot 24 \mathrm{~mm}$ diameter; mean $\pm \mathrm{SE}$, $n=30)$ and CM972 (1.55 $\pm 0.79 \mathrm{~mm}$ diameter; mean $\pm \mathrm{SE}, \quad n=30$ ) in McCoy cell monolayers cultured in parallel, after 5 days incubation at $37^{\circ} \mathrm{C}, 5 \% \mathrm{CO}_{2}$. The solid overlay was removed and the cells stained with neutral red before being photographed. reduced ability to replicate within McCoy cells, we compared, in parallel experiments, the infectious yield of both strains when grown in culture with an m.o.i. of 0.5 and no difference was observed (Nigg: $3 \cdot 45 \times 10^{7} \pm 6 \cdot 39 \times$ $10^{6}$ i.f.u. $\mathrm{ml}^{-1}$ vs strain CM972: $4 \cdot 24 \times 10^{7} \pm 7 \cdot 58 \times 10^{6}$ i.f.u. $\mathrm{ml}^{-1}$; means $\pm \mathrm{SE}$ ), suggesting that once inside the cell, both strains replicate and form infectious progeny equally well.

\section{DISCUSSION}

This paper describes the isolation of plasmid-deficient derivatives of $C$. muridarum strain Nigg, using novobiocin as a curing agent. Plasmid-deficient derivatives created by this method resemble naturally occurring plasmid-deficient strains in their inability to accumulate glycogen within intracytoplasmic inclusions. In addition we describe a novel phenotype, poor plaquing efficiency, which was observed for all plasmid-deficient strains of $C$. trachomatis.

\section{Novobiocin is an effective curing agent for chlamydiae}

The ability to cure C. muridarum strain Nigg would suggest that, at appropriate concentrations of novobiocin, plasmid replication is sufficiently inhibited that plasmid-deficient isolates can be recovered; this is in contrast to previous reports that at low concentrations of the drug $\left(20 \mu \mathrm{g} \mathrm{ml}^{-1}\right.$ in conjunction with $20 \mu \mathrm{g}$ imipramine $\mathrm{ml}^{-1}$ ), plasmid copy number increases (Pickett et al., 2005). The apparently elevated concentrations of novobiocin required to suppress chlamydial replication were striking. However, each of the chlamydial strains for which genome sequencing has been completed [C. trachomatis strain D/UW-3Cx (Stephens et al., 1998), C. trachomatis strain A/HAR-13 (Carlson et al., 2005) and C. muridarum strain Nigg (Read et al., 2000)] carries phospholipase D family orthologues (CT154-158; CTA_0163-0167 and TC0432-436; TC0440, respectively). In Escherichia coli, phospholipase D is encoded by cls. The cls gene has been recognized as identical to the wild-type form of the nov allele (Tropp et al., 1995) and mutations in nov are associated with greatly enhanced novobiocin sensitivity as a consequence of changes in outer-membrane lipid structure which affect permeability. Thus it is possible that the amount of novobiocin that was required to trigger plasmid loss by chlamydiae may reflect a level of intrinsic resistance due to the relative impermeability of the chlamydial outer membrane. Nonetheless, the effective concentration of novobiocin required for plasmid curing was not cytotoxic, enabling the enrichment of plasmid-deficient bacteria. The use of novobiocin as a plasmid-curing agent is highly effective and allows the recovery of plasmid-deficient derivatives at high frequency. This technique should be generally applicable to other $C$. trachomatis strains or other plasmid-containing Chlamydia species.

\section{Plasmid-deficient chlamydiae are less able to form plaques in cell culture}

It would appear that a reduced ability to form plaques in cell culture is associated with plasmid loss from C. trachomatis. Previously identified plasmid-deficient clinical isolates (Peterson et al., 1990; Stothard et al., 1998) that are available for study also failed to plaque in our assay (data not shown). However, the absence of an isogenic, plasmidcontaining parental control for these clinical isolates made the significance of these observations difficult to interpret. Our observations that plasmid-deficient isolates were only recovered after novobiocin treatment if the bacteria were passed via centrifugation at all steps are consistent with those of Matsumoto et al. (1998), who reported the recovery of plasmid-deficient derivatives of in vitro-cultured strains with little difficulty. It is noteworthy that centrifugation of the inoculum onto the cells was an integral component of all screening and passage steps in their protocols. The parental strain Nigg demonstrates a marked reduction in plaquing efficiency if applied to monolayers without centrifugation. The significance of this observation is not clear; it may reflect strain-specific or receptor-specific variations in attachment or uptake into cells as has been described for other chlamydial strains (Chen \& Stephens, 1997; Davis et al., 2002; Carabeo \& Hackstadt, 2001). However, a more profound deficiency in the ability to plaque under these conditions is demonstrated by strain CM972; this suggests 
that plasmid-deficient derivatives may be selected against under some culture conditions, and particularly when the plaque assay protocols that are used for isolation and screening do not involve centrifugation of the monolayer. We also noted that plaques formed by CM972 were one-half the diameter of the plaques of the parent strain. This is likely a further reflection of the attachment/uptake defect manifested by this strain because plaque size may reflect the relative efficiency with which the bacteria undergo subsequent rounds of uptake and amplification in the host cells immediately adjacent to the focus of infection.

Plaque size is highly variable between experiments and is known to be influenced by many other factors including the overall quality of the cell monolayer, the culture medium and the length of time the plaque assays are maintained in culture. This may affect the rate at which plasmid-deficient isolates are recovered from a novobiocin-treated population, possibly leading to variable estimates of curing efficiency: low if overall plaque size is small; higher if overall plaque size is larger. It was not possible to estimate the rate of natural plasmid loss by C. muridarum strain Nigg because we failed to identify any naturally cured derivatives.

\section{The role of the cryptic plasmid in chlamydiae}

Loss of the plasmid is associated with two distinct and possibly unrelated phenotypes (glycogen accumulation, efficiency of plaque formation), raising the possibility that a regulator or co-factor for genes important for these phenotypes may be encoded on the plasmid. Nonetheless, the significance of these phenotypes to chlamydial infection is unclear. We have observed that a variety of environmental factors can suppress the accumulation of glycogen within inclusions, including ampicillin treatment and substrate limitation (unpublished). Furthermore, it should be noted that neither Chlamydophila psittaci nor Chlamydophila pneumoniae accumulate glycogen within their inclusions, although the majority of C. psittaci and some C. pneumoniae strains carry the plasmid (Lusher et al., 1989; Thomas et al., 1997; McClenaghan et al., 1988) and the glycogen metabolic genes have been retained on the chromosome (Read et al., 2000, 2003; Kalman et al., 1999). It would be highly desirable to reintroduce the cryptic plasmid into $C$. muridarum and demonstrate restoration of both intra-inclusion glycogen accumulation and plaquing efficiency. However, an effective gene transformation system has yet to be developed for the chlamydiae.

Although it has been noted that centrifugation of the chlamydial inoculum onto cell monolayers can increase the efficiency with which cells may become infected (Rota, 1977; Lee, 1981; Pearce et al., 1981), it is difficult to envisage how this manipulation might mimic a relevant in vivo condition. Our isolation of a plasmid-deficient variant of the mousevirulent $C$. muridarum Nigg will enable us to investigate whether loss of the cryptic plasmid affects the ability of the bacterium to establish infection. In addition, it is possible that the plaquing defect that we have observed may ultimately be used as the basis for a positive selection for transformants.

\section{ACKNOWLEDGEMENTS}

The authors gratefully acknowledge the generous gift of M40 monoclonal antibody by Dr Ellena Peterson. The authors also wish to thank Drs Roger Rank, Toni Darville, Uma Nagarajan, Marie Chow and Ming Tan for helpful discussions. Catherine O'Connell also wishes to recognize the encouragement and support of You-xun Zhang and Peter Rice MD during the initial phases of this project. This work was supported by grants from NIH/NIAID, A145565 and A138515.

\section{REFERENCES}

Banks, J., Eddie, B., Schachter, J. \& Meyer, K. F. (1970). Plaque formation by Chlamydia in L cells. Infect Immun 1, 259-262.

Belland, R. J., Zhong, G., Crane, D. D., Hogan, D., Sturdevant, D., Sharma, J., Beatty, W. L. \& Caldwell, H. D. (2003). Genomic transcriptional profiling of the developmental cycle of Chlamydia trachomatis. Proc Natl Acad Sci U S A 100, 8478-8483.

Carabeo, R. A. \& Hackstadt, T. (2001). Isolation and characterization of a mutant Chinese hamster ovary cell line that is resistant to Chlamydia trachomatis infection at a novel step in the attachment process. Infect Immun 69, 5899-5904.

Carlson, J. H., Porcella, S. F., McClarty, G. \& Caldwell, H. D. (2005). Comparative genomic analysis of Chlamydia trachomatis oculotropic and genitotropic strains. Infect Immun 73, 6407-6418.

Chen, J. C. \& Stephens, R. S. (1997). Chlamydia trachomatis glycosaminoglycan-dependent and independent attachment to eukaryotic cells. Microb Pathog 22, 23-30.

Comanducci, M., Cevenini, R., Moroni, A., Giuliani, M. M., Ricci, S., Scarlato, V. \& Ratti, G. (1993). Expression of a plasmid gene of Chlamydia trachomatis encoding a novel $28 \mathrm{kDa}$ antigen. J Gen Microbiol 139, 1083-1092.

Davis, C. H., Raulston, J. E. \& Wyrick, P. B. (2002). Protein disulfide isomerase, a component of the estrogen receptor complex, is associated with Chlamydia trachomatis serovar E attached to human endometrial epithelial cells. Infect Immun 70, 3413-3418.

Dean, D., Oudens, E., Bolan, G., Padian, N. \& Schachter, J. (1995). Major outer membrane protein variants of Chlamydia trachomatis are associated with severe upper genital tract infections and histopathology in San Francisco. J Infect Dis 172, 1013-1022.

Fahr, M. J., Sriprakash, K. S. \& Hatch, T. P. (1992). Convergent and overlapping transcripts of the Chlamydia trachomatis $7 \cdot 5-\mathrm{kb}$ plasmid. Plasmid 28, 247-257.

Farencena, A., Comanducci, M., Donati, M., Ratti, G. \& Cevenini, R. (1997). Characterization of a new isolate of Chlamydia trachomatis which lacks the common plasmid and has properties of biovar trachoma. Infect Immun 65, 2965-2969.

Gado, I., Toth, I. \& Szvoboda, G. (1987). Curing of plasmid pE194 with novobiocin and coumermycin A1 in Bacillus subtilis and Staphylococcus aureus. Zentralbl Bakteriol Mikrobiol Hyg A 265, 136-145.

Hooper, D. C., Wolfson, J. S., McHugh, G. L., Swartz, M. D., Tung, C. \& Swartz, M. N. (1984). Elimination of plasmid pMG110 from Escherichia coli by novobiocin and other inhibitors of DNA gyrase. Antimicrob Agents Chemother 25, 586-590.

Hussy, P., Maass, G., Tummler, B., Grosse, F. \& Schomburg, U. (1986). Effect of 4-quinolones and novobiocin on calf thymus DNA polymerase alpha primase complex, topoisomerases I and II, and 
growth of mammalian lymphoblasts. Antimicrob Agents Chemother 29, 1073-1078.

Kalman, S., Mitchell, W., Marathe, R. \& 7 other authors (1999). Comparative genomes of Chlamydia pneumoniae and C. trachomatis. Nat Genet 21, 385-389.

Kelly, K. A., Robinson, E. A. \& Rank, R. G. (1996). Initial route of antigen administration alters the $\mathrm{T}$-cell cytokine profile produced in response to the mouse pneumonitis biovar of Chlamydia trachomatis following genital infection. Infect Immun 64, 4976-4983.

Lee, C. K. (1981). Interaction between a trachoma strain of Chlamydia trachomatis and mouse fibroblasts (McCoy cells) in the absence of centrifugation. Infect Immun 31, 584-591.

Lusher, M., Storey, C. C. \& Richmond, S. J. (1989). Plasmid diversity within the genus Chlamydia. J Gen Microbiol 135 (Pt 5), 1145-1151.

Luttinger, A. (1995). The twisted 'life' of DNA in the cell: bacterial topoisomerases. Mol Microbiol 15, 601-606.

Matsumoto, A., Izutsu, H., Miyashita, N. \& Ohuchi, M. (1998). Plaque formation by and plaque cloning of Chlamydia trachomatis biovar trachoma. J Clin Microbiol 36, 3013-3019.

McClenaghan, M., Honeycombe, J. R., Bevan, B. J. \& Herring, A. J. (1988). Distribution of plasmid sequences in avian and mammalian strains of Chlamydia psittaci. J Gen Microbiol 134, 559-565.

Miyashita, N., Matsumoto, A. \& Matsushima, T. (2000). In vitro susceptibility of $7 \cdot 5-\mathrm{kb}$ common plasmid-free Chlamydia trachomatis strains. Microbiol Immunol 44, 267-269.

Nigg, C. (1942). An unidentified virus which produces pneumonia and systemic infection in mice. Science 95, 49-50.

O'Connell, C. M. C. \& Maurelli, A. T. (1998). Introduction of Foreign DNA into Chlamydia and Stable Expression of Chloramphenicol Resistance, pp. 519-522. San Francisco, CA: International Chlamydial Symposium.

Pearce, J. H., Allan, I. \& Ainsworth, S. (1981). Interaction of chlamydiae with host cells and mucous surfaces. Ciba Found Symp 80, 234-249.

Pearce, B. J., Fahr, M. J., Hatch, T. P. \& Sriprakash, K. S. (1991). A chlamydial plasmid is differentially transcribed during the life cycle of Chlamydia trachomatis. Plasmid 26, 116-122.
Peterson, E. M., Markoff, B. A., Schachter, J. \& De La Maza, L. M. (1990). The $7 \cdot 5-\mathrm{kb}$ plasmid present in Chlamydia trachomatis is not essential for the growth of this microorganism. Plasmid 23, 144-148.

Pickett, M. A., Everson, J. S., Pead, P. J. \& Clarke, I. N. (2005). The plasmids of Chlamydia trachomatis and Chlamydophila pneumoniae (N16): accurate determination of copy number and the paradoxical effect of plasmid-curing agents. Microbiology 151, 893-903.

Read, T. D., Brunham, R. C., Shen, C. \& 22 other authors (2000). Genome sequences of Chlamydia trachomatis MoPn and Chlamydia pneumoniae AR39. Nucleic Acids Res 28, 1397-1406.

Read, T. D., Myers, G. S., Brunham, R. C. \& 18 other authors (2003). Genome sequence of Chlamydiophila caviae (Chlamydia psittaci GPIC): examining the role of niche-specific genes in the evolution of the Chlamydiaceae. Nucleic Acids Res 31, 2134-2147.

Rota, T. R. (1977). Chlamydia trachomatis in cell culture. II. Susceptibility of seven established mammalian cell types in vitro. Adaptation of trachoma organisms to McCoy and BHK-21 cells. In Vitro 13, 280-292.

Schachter, J. \& Dawson, C. R. (1978). Laboratory diagnosis. In Human Chlamydial Infections, pp. 181-220. Littleton, MA: PSG Publishing Co.

Stephens, R. S., Kalman, S. \& Lammel, C. (1998). Genome sequence of an obligate intracellular pathogen of humans: Chlamydia trachomatis. Science 282, 754-759.

Stothard, D. R., Williams, J. A., Van Der Pol, B. \& Jones, R. B. (1998). Identification of a Chlamydia trachomatis serovar E urogenital isolate which lacks the cryptic plasmid. Infect Immun 66, 6010-6013.

Tam, J. E., Davis, C. H., Thresher, R. J. \& Wyrick, P. B. (1992). Location of the origin of replication for the $7 \cdot 5-\mathrm{kb}$ Chlamydia trachomatis plasmid. Plasmid 27, 231-236.

Thomas, N. S., Lusher, M., Storey, C. C. \& Clarke, I. N. (1997). Plasmid diversity in Chlamydia. Microbiology 143, 1847-1854.

Tropp, B. E., Ragolia, L., Xia, W., Dowhan, W., Milkman, R., Rudd, K. E., Ivanisevic, R. \& Savic, D. J. (1995). Identity of the Escherichia coli cls and nov genes. J Bacteriol 177, 5155-5157.

Wolfson, J. S., Hooper, D. C., Swartz, M. N., Swartz, M. D. \& McHugh, G. L. (1983). Novobiocin-induced elimination of $F^{\prime} l a c$ and mini-F plasmids from Escherichia coli. J Bacteriol 156, 1165-1170. 